\title{
Communication
}

\section{Multiple-Timescale Dynamics of Side-Chain Carboxyl and Carbonyl Groups in Proteins by C Nuclear Spin Relaxation}

Raphae\#l Paquin, Fabien Ferrage, Frans A. A. Mulder, Mikael Akke, and Geoffrey Bodenhausen J. Am. Chem. Soc., 2008, 130 (47), 15805-15807• DOI: 10.1021/ja803794g • Publication Date (Web): 31 October 2008

Downloaded from http://pubs.acs.org on May 14, 2009
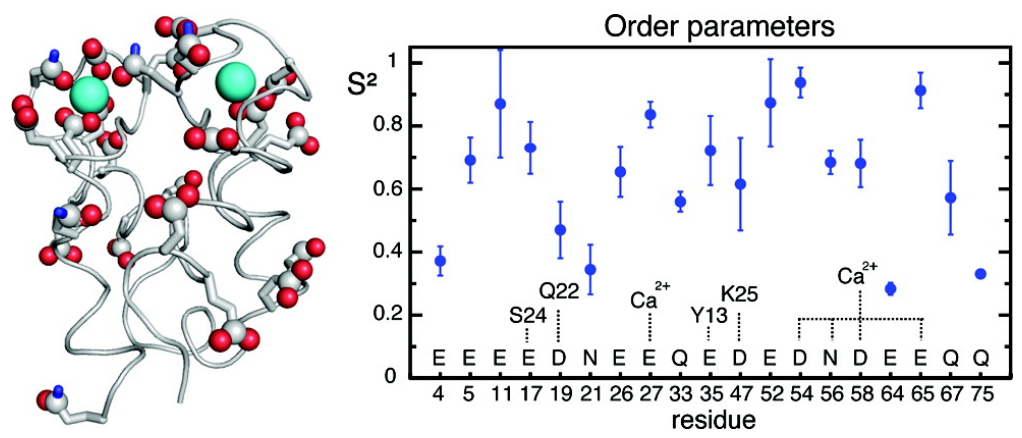

\section{More About This Article}

Additional resources and features associated with this article are available within the HTML version:

- Supporting Information

- $\quad$ Links to the 1 articles that cite this article, as of the time of this article download

- Access to high resolution figures

- $\quad$ Links to articles and content related to this article

- Copyright permission to reproduce figures and/or text from this article

\section{View the Full Text HTML}




\title{
Multiple-Timescale Dynamics of Side-Chain Carboxyl and Carbonyl Groups in Proteins by ${ }^{13} \mathrm{C}$ Nuclear Spin Relaxation
}

\author{
Raphaël Paquin, ${ }^{\dagger, \|}$ Fabien Ferrage, ${ }^{*, \dagger}$ Frans A. A. Mulder, ${ }^{, \dagger}$ Mikael Akke, ${ }^{\S}$ and \\ Geoffrey Bodenhausen ${ }^{\dagger, 11}$ \\ Département de Chimie, associé au CNRS, Ecole Normale Supérieure, 24, rue Lhomond, 75231 Paris Cedex 05, \\ France, Biophysical Chemistry, University of Groningen, Nijenborgh 4, 9747 AG Groningen, The Netherlands, \\ Center for Molecular Protein Science, Division of Biophysical Chemistry, Department of Chemistry, Lund \\ University, P.O. Box 124, SE-221 00 Lund, Sweden, and Institut des Sciences et Ingénierie Chimiques, Ecole \\ Polytechnique Fédérale de Lausanne, BCH, CH-1015 Lausanne, Switzerland
}

Received May 21, 2008; E-mail: Fabien.Ferrage@ens.fr; f.a.a.mulder@rug.nl

Nuclear magnetic resonance (NMR) can give a measure of the frequencies and amplitudes of motions of individual atoms in proteins on time scales ranging from picoseconds to days. ${ }^{1-7}$ Most popular NMR experiments focus on the dynamics of protein backbones. So far, investigations of side-chain dynamics have mostly focused on methyl groups, ${ }^{8-12}$ although other aliphatic ${ }^{13}$ and $\operatorname{aromatic}^{14,15}$ groups as well as hydrophilic side chains containing amide ${ }^{16-18}$ and guanidino ${ }^{19,20}$ groups have also been studied. Recent work has shown that fast proton exchange rates can be determined in arginine and lysine side chains. ${ }^{21,22}$ On the other hand, the dynamics of side-chain carboxyl and carbonyl groups have not been studied in detail despite their obvious importance for ligand binding, catalysis, and other biological functions. Here, we introduce a set of ${ }^{13} \mathrm{C}$ relaxation experiments designed to sample the dynamics of amide carbonyl and carboxyl groups in the side chains of aspartic acid (D), asparagine (N), glutamic acid $(\mathrm{E})$, and glutamine $(\mathrm{Q})$ by monitoring relaxation rates of ${ }^{13} \mathrm{C}^{\gamma}$ in $\mathrm{D} / \mathrm{N}$ and ${ }^{13} \mathrm{C}^{\delta}$ in $\mathrm{E} / \mathrm{Q}$. Our approach is illustrated by the calcium-binding protein calbindin $\mathrm{D}_{9 \mathrm{k}} \mathrm{P} 43 \mathrm{G}$ which contains several carboxyl and carbonyl groups that ligate the calcium ions. ${ }^{23}$

We have measured the longitudinal relaxation rates $\left(R_{1}\right)$ of sidechain carboxyl and carbonyl ${ }^{13} \mathrm{C}$ nuclei $\left({ }^{13} \mathrm{C}^{\prime}\right)$, their rotating-frame relaxation rates $\left(R_{1 \rho}\right)$ as a function of offset, and the cross-relaxation rates $\left(\eta_{x y}\right)$ due to the cross-correlation of their chemical shift anisotropy (CSA) and the dipolar coupling with the adjacent ${ }^{13} \mathrm{C}$ nucleus. Expressions for these rates are given in the Supporting Information (SI).

The pulse sequence employed for $R_{1 \rho}$ measurements is presented in Figure 1; the corresponding sequences used to measure $R_{1}$ and $\eta_{x y}$ are given in the SI. Although direct ${ }^{13} \mathrm{C}$ detection can be employed, ${ }^{24}$ we used more sensitive out-and-back experiments where the ${ }^{1} \mathrm{H}$ polarization of the adjacent methylene protons was transferred via the methylene ${ }^{13} \mathrm{C}$ to the carboxyl/carbonyl ${ }^{13} \mathrm{C}$. The continuous wave irradiation applied in the $R_{1 \rho}$ experiments attenuates undesirable effects of ${ }^{13} \mathrm{C}-{ }^{13} \mathrm{C}$ scalar couplings. ${ }^{25,26}$ The alignment method of Hansen and $\mathrm{Kay}^{27}$ was employed for $R_{1 \rho}$ measurements close to resonance, while adiabiatic alignment was implemented to access a broader range of offsets. ${ }^{28}$ The scheme of Massi et al. ${ }^{29}$ suppresses the effects of CSA/DD crosscorrelations without perturbing the spin-lock RF field. This scheme also allows one to use low spin-lock RF amplitudes for the study of slow exchange processes. During the relaxation delays, undesired

\footnotetext{
Ecole Normale Supérieure.

"Ecole Polytechnique Fédérale de Lausanne.

* Groningen University.

\&und University.
}

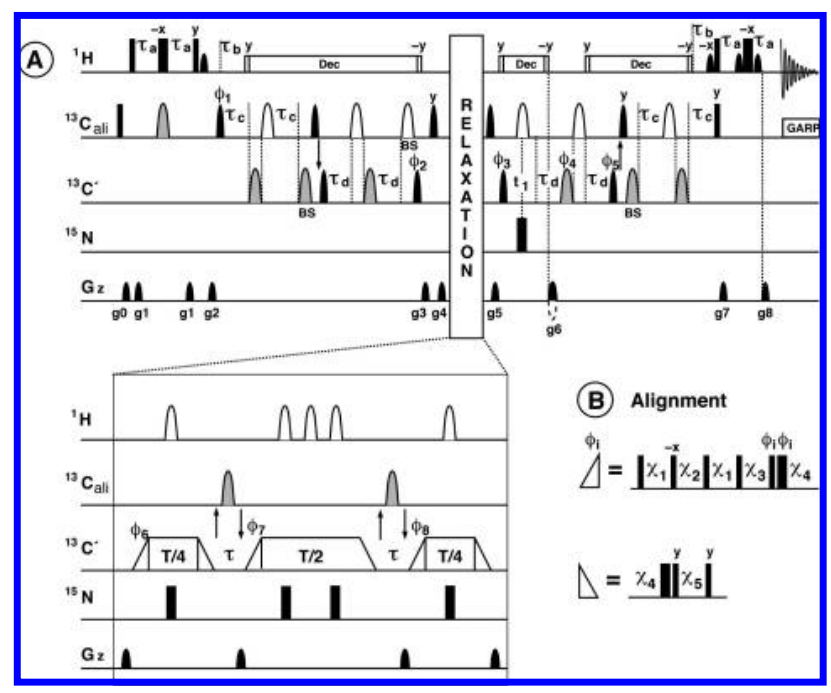

Figure 1. (A) Pulse sequence used to measure the rotating-frame relaxation rates $R_{1 \rho}$ of side-chain carboxyl/carbonyl ${ }^{13} \mathrm{C}$ nuclei. (B) Alignment schemes. ${ }^{27}$ Narrow and wide black rectangles correspond to $90^{\circ}$ and $180^{\circ}$ pulses, respectively. Pulses are applied with phase $x$ unless otherwise indicated. The ${ }^{1} \mathrm{H}$ carrier was placed on the water resonance $(4.7 \mathrm{ppm})$. Arrows between the ${ }^{13} \mathrm{C}$ channels indicate a change of carrier frequency. DIPSI- $2^{32}$ and GARP ${ }^{30}$ were used for ${ }^{1} \mathrm{H}$ and ${ }^{13} \mathrm{C}$ decoupling. Waterselective sinc-shaped $90^{\circ}$ pulses are represented by filled bell shapes. ${ }^{1} \mathrm{H}$ REBURP $^{31}$ pulses (open bell shapes) were applied during the relaxation period. Narrow black and wide gray bell shapes on the ${ }^{13} \mathrm{C}$ channel represent Q5 and Q3 shaped pulses, ${ }^{33}$ respectively. "BS" indicates Bloch-Siegert compensation pulses. ${ }^{34}$ Relaxation delays were $T=24,72,96$, and 144 ms. A series of rates were recorded with the spin-lock carrier shifted from 172 to $186 \mathrm{ppm}$ in $2 \mathrm{ppm}$ steps. The amplitudes $(\mathrm{G} / \mathrm{cm})$ and durations $(\mathrm{ms})$ of the $z$-gradients were: g0: $7 ; 0.5 ; \mathrm{g} 1: 6 ; 0.5 ; \mathrm{g} 2: 28 ; 2.4 ; \mathrm{g} 3: 7 ; 0.64 ; \mathrm{g} 4$ : 5; 0.5; g5: 23; 0.5; g6: 23; 2.0; g7: $-9 ; 0.5 ;$ g8: $-31 ; 0.5$. The phase cycles were: $\varphi_{1}=\{x,-x\} ; \varphi_{2}=2\{y\}, 2\{-y\} ; \varphi_{3}=4\{y\}, 4\{-y\} ; \varphi_{4}=x ; \varphi_{5}=$ $x ; \varphi_{6}=8\{x\}, 8\{-x\} ; \varphi_{7}=16\{x\}, 16\{-x\} ; \varphi_{8}=32\{x\}, 32\{-x\} . \varphi_{\text {rec }}=$ $\{\{x\}, 2\{-x\},\{x\}\}, 2 \times\{\{-x\}, 2\{x\},\{-x\}\},\{\{x\}, 2\{-x\},\{x\}\}, 2 \times$ $\{\{-x\}, 2\{x\},\{-x\}\}, 2 \times\{\{x\}, 2\{-x\},\{x\}\},\{\{-x\}, 2\{x\},\{-x\}\},\{\{x\}$, $2\{-x\},\{x\}\}, 2 \times\{\{-x\}, 2\{x\},\{-x\}\},\{\{x\}, 2\{-x\},\{x\}\}$. Quadrature detection in the ${ }^{13} \mathrm{C}$ dimension was performed by recording two data sets with $\left(\varphi_{3}, \mathrm{~g} 6\right)$ and $\left(-\varphi_{3},-\mathrm{g} 6\right)$ for each $t_{1}$ point. Delays were as follows: $\tau_{\mathrm{a}}$ $=\tau_{\mathrm{b}}=1 /\left(4 J_{\mathrm{CH}}\right)=1.8 \mathrm{~ms}$, or $\tau_{\mathrm{b}}=1 /\left(2 J_{\mathrm{CH}}\right)=3.6 \mathrm{~ms}$ for the selection of CHD groups; $\tau_{\mathrm{c}}=3 \mathrm{~ms} ; \tau_{\mathrm{d}}=1 /\left(4 J_{\mathrm{CC}}\right)=5 \mathrm{~ms}$ ( $3 \mathrm{~ms}$ were used $)$. Further details are given in the SI.

cross-relaxation pathways ${ }^{35-37}$ were suppressed by applying $\pi$ pulses to ${ }^{1} \mathrm{H},{ }^{15} \mathrm{~N}$, and aliphatic ${ }^{13} \mathrm{C}$ nuclei. Depending on the level of deuteration, maximum signals can be obtained for delays $1 /\left(4 J_{\mathrm{CH}}\right)$ $<\tau_{\mathrm{b}}<1 /\left(2 J_{\mathrm{CH}}\right)$, i.e., between the optimal values for $\mathrm{CH}_{2}$ and $\mathrm{CHD}$ groups, respectively. A refocused INEPT in a $\mathrm{CH}_{2}$ group, with $\tau_{\mathrm{b}}$ $=1 /\left(4 J_{\mathrm{CH}}\right)$, generates, in addition to the desired in-phase ${ }^{13} \mathrm{C}$ 


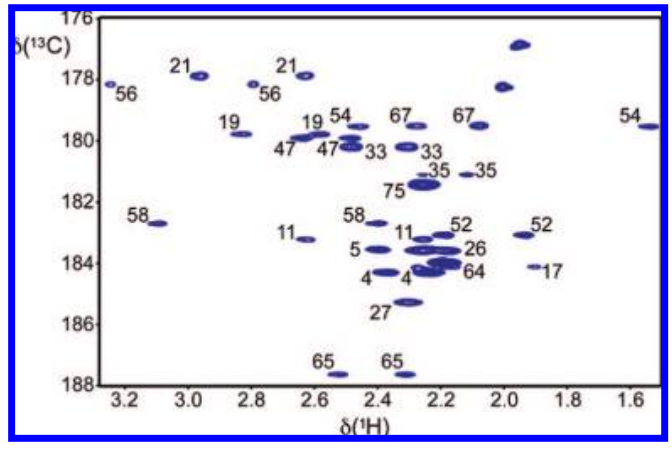

Figure 2. $\mathrm{H}(\mathrm{C}) \mathrm{CO}$ spectrum of calbindin $\mathrm{D}_{9 \mathrm{k}}$. Assignments are shown for all peaks analyzed in this study.

coherence, a doubly antiphase ${ }^{13} \mathrm{C}$ coherence that leads to artifacts in slowly relaxing systems (e.g., Q75, see SI). The use of $\tau_{\mathrm{b}}=$ $1 /\left(2 J_{\mathrm{CH}}\right)$ provides maximum accuracy when supplemented with a filter for CHD moieties (see SI). In addition, the quantification of dipolar interactions with neighboring protons becomes straightforward and spectral resolution is improved (see SI). Under these conditions, maximum sensitivity is achieved with a $50 \%$ level of deuteration. The cross-relaxation rate $\eta_{x y}$ was measured using symmetrical reconversion. ${ }^{38}$

A $\left[{ }^{15} \mathrm{~N},{ }^{13} \mathrm{C},{ }^{2} \mathrm{H}(50 \%)\right]$-labeled sample of calbindin $\mathrm{D}_{9 \mathrm{k}} \mathrm{P} 43 \mathrm{G}$ was studied at $296 \mathrm{~K}$ and $\mathrm{pH} 6.0(100 \mu \mathrm{L}$ at $4 \mathrm{mM}$ concentration). The ${ }^{13} \mathrm{C}^{\prime} R_{1}, R_{1 \rho}$, and $\eta_{x y}$ rates were measured using a Bruker Avance $600 \mathrm{MHz}$ spectrometer equipped with a triple-gradient TBI probe. A set of ${ }^{13} \mathrm{C}^{\prime} R_{1}$ data was collected on a Bruker Avance 500 equipped with a TCI cryoprobe. The ${ }^{13} \mathrm{C}^{\prime} R_{1}$ and $R_{1 \rho}$ rates were also measured at $301 \mathrm{~K}$ on a Varian Inova $500 \mathrm{MHz}$ spectrometer. A typical 2D-H(C)CO spectrum is shown in Figure 2.

Model-free ${ }^{39}$ analysis of the ${ }^{13} \mathrm{C}^{\prime}$ relaxation rates involved a simultaneous two-parameter fit of the order parameter $S^{2}$ and the correlation time $\tau_{e}$ of local motions against the rates $R_{1}(500)$, $R_{1}(600)$, and $\eta_{x y}(600)$. The overall rotational diffusion of calbindin $\mathrm{D}_{9 \mathrm{k}}$ is known to be isotropic with a correlation time $\tau_{\mathrm{c}}=4.17 \mathrm{~ns}$ at $296 \mathrm{~K}$, as determined from backbone ${ }^{15} \mathrm{~N}$ relaxation data; $\tau_{\mathrm{c}}$ was fixed at this value in the model-free analysis. The local motions were also assumed to be isotropic, in the sense that the amplitudes of the angular fluctuations of a vector were assumed to be independent of its orientation, so that a common model-free spectral density function ${ }^{39} J(\omega)$ could be used for all interactions. The exchange contributions $\left(R_{\mathrm{ex}}\right)$ to the line widths were extracted from a comparison of $R_{2}(600)$ and the exchange-free transverse relaxation rates $R_{2}^{0}$ calculated from fitted model-free parameters.

The model-free analysis depends on the parametrization of the CSA tensors. For the side-chain carbonyl ${ }^{13} \mathrm{C}$, we used the average CSA values determined in ubiquitin ${ }^{40}$ for the backbone amide carbonyl ${ }^{13} \mathrm{C}$ : $\sigma_{x x}=251.8, \sigma_{y y}=203.25$, and $\sigma_{z z}=83.6 \mathrm{ppm}$, where the latter component is perpendicular to the plane spanned by the $\mathrm{C}-\mathrm{C}$ and $\mathrm{C}=\mathrm{O}$ bonds, and the $\sigma_{x x}$ component subtends an angle of $25^{\circ}$ with the $\mathrm{C}-\mathrm{C}$ bond. For the carboxyl ${ }^{13} \mathrm{C}$, the principal components of the CSA tensors were assumed to be ${ }^{41} \sigma_{x x}=242$, $\sigma_{y y}=191$, and $\sigma_{z z}=105 \mathrm{ppm}$, with the $\sigma_{x x}$ component being parallel to the $\mathrm{C}-\mathrm{C}$ bond. The model-free analysis was repeated with extreme values for the CSA components of carboxyl groups. ${ }^{42}$ The variations of carbonyl CSA components were related to the range of isotropic chemical shifts. ${ }^{40}$ The resulting variations of the extracted model-free parameters are small for carboxyl and negligible for carbonyl groups (see SI). The robustness of our analysis originates from the linear (rather than quadratic) depen-

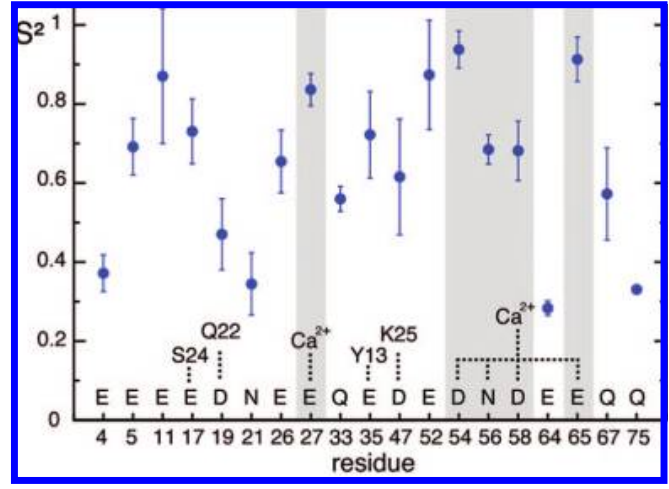

Figure 3. Order parameters $\mathrm{S}^{2}$ determined by model-free analysis of the relaxation rates of ${ }^{13} \mathrm{C}$ nuclei in carboxyl and amide carbonyl groups in the side chains of aspartic acid (D), asparagine (N), glutamic acid (E), and glutamine $(\mathrm{Q})$ residues. Residues involved in $\mathrm{Ca}^{2+}$ coordination, $\mathrm{H}$-bonds, or electrostatic interactions are indicated together with the interaction partner.

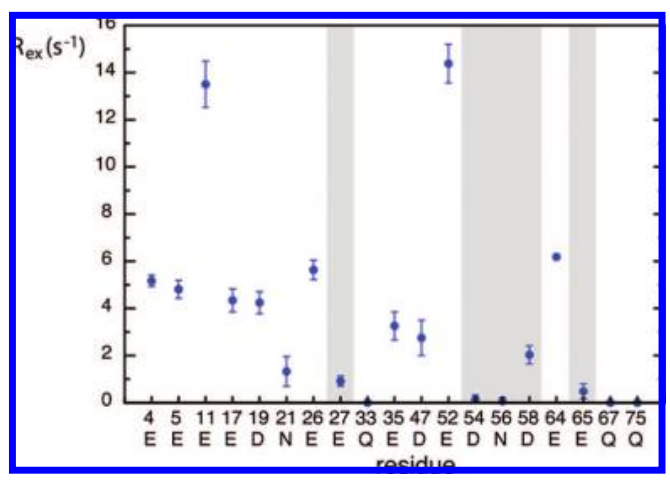

Figure 4. Contributions $R_{\mathrm{ex}}$ to the line widths of side-chain carbonyl/ carboxyl ${ }^{13} \mathrm{C}$ nuclei due to chemical exchange processes. Side chains that act as ligands for calcium binding are indicated by shaded bars.

dence of $\eta_{x y}$ rates upon CSA components as well as a favorable orientation of the CSA tensors: the angle between the $\mathrm{C}-\mathrm{C}$ bond and the variable CSA component is $90^{\circ}$ for carboxyl and close to the magic angle for carbonyl ${ }^{13} \mathrm{C}$. The influence of this orientation remains to be evaluated.

As shown in Figure 3, the order parameters indicate a rigid behavior of all side chains that are involved in $\mathrm{Ca}^{2+}$ binding (E27, D54, N56, E58, E65), with $0.68<S^{2}<0.94$. Relatively high order parameters $\left(S^{2}>0.61\right)$ are also observed for groups that are either hydrogen bonded or involved in an electrostatic interaction in the crystal structure, ${ }^{23}$ i.e., E17 (H-bonded to S24 O ${ }^{\gamma} \mathrm{H}$ ), E35 (to Y13 $\mathrm{O}^{\eta} \mathrm{H}$ ), and $\mathrm{D} 47$ (to $\mathrm{K} 25 \mathrm{~N}^{\xi} \mathrm{H}_{3}{ }^{+}$), with the exception of D19 (to Q22 $\left.\mathrm{N}^{\epsilon} \mathrm{H}\right)$, while lower order parameters $\left(S^{2}<0.66\right)$ are observed for side chains that are exposed to the solvent (E4, N21, E26, Q33, E64, Q67, and Q75). E5 features a surprising rigidity that could not be rationalized so far. The order parameters of E11 and E52 are likely to be overestimated because low intensities in the $\eta_{x y}$ experiments lead to poor sampling of the spectral density function at low frequency. Future work could involve complementary studies of relaxation interference in methylene groups. ${ }^{43,44}$

Figure 4 shows contributions to the ${ }^{13} \mathrm{C}^{\prime}$ line widths due to chemical exchange processes in the range from $\mu$ s to ms. No $\mu \mathrm{s}$ time scale conformational exchange was detected so far in calcium-loaded calbindin $\mathrm{D}_{9 \mathrm{k}} \mathrm{P} 43 \mathrm{G} .^{26,45} \mathrm{We}$ attribute these effects to an interchange between the dominant basic and minor protonated forms of the carboxyl groups at $\mathrm{pH} 6.0{ }^{46}$ This hypothesis is supported by the fact that $R_{\mathrm{ex}}$ is negligible for the 


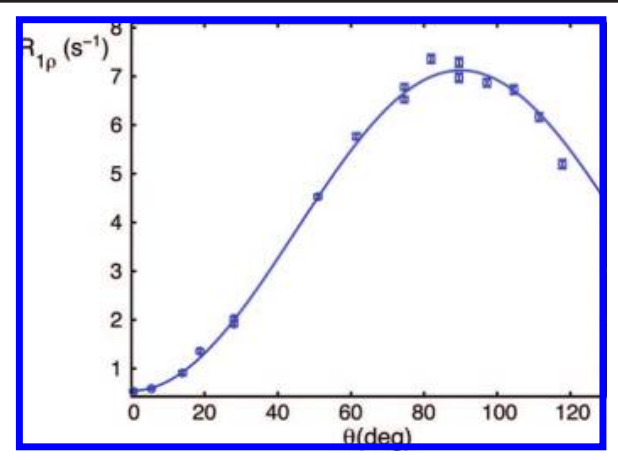

Figure 5. Typical angular dependence of the rotating frame relaxation rate $R_{1 \rho}$ of ${ }^{13} \mathrm{C}^{\delta}$ in E64 ( $T=301 \mathrm{~K} ; \mathrm{B}_{0}=11.7 \mathrm{~T} ; 1.9 \mathrm{kHz} \mathrm{RF}$ amplitude). $\theta$ is the tilt angle of the effective field in the rotating frame. Experimental data (circles) were fitted (plain line) with only two parameters $\left(R_{1}\right.$ and $\left.R_{2}\right)$.

amide carbonyl ${ }^{13} \mathrm{C}$ and small for carboxyl groups involved in $\mathrm{Ca}^{2+}$ binding, for which the equilibrium is heavily shifted toward the basic form. We found a significant correlation between $R_{\text {ex }}$ and the populations derived from the $\mathrm{p} K_{\mathrm{a}}$ measured in $\mathrm{Ca}^{2+}$ free calbindin ${ }^{46}$ for carboxyl groups that are not involved in calcium binding (see SI). The large $R_{\mathrm{ex}}$ values for ${ }^{13} \mathrm{C}^{\delta}$ in $\mathrm{E} 11$ and E52 are likely due to an increased population of the protonated state, i.e. an upward shift in their $\mathrm{p} K_{\mathrm{a}}$ as compared to values characteristic of unstructured peptides. ${ }^{46}$ Experiments at a different $\mathrm{pH}$ will be carried out to test this hypothesis. Figure 5 shows the variation of $R_{1 \rho}$ with the tilt angle $(\theta)$ of the effective field for ${ }^{13} \mathrm{C}^{\delta}$ of E64. Similar data could be fitted for all residues without invoking any $\theta$-dependence of $R_{2}$, thus revealing that the exchange processes must be very fast, with rates $k_{\text {ex }}>10^{4} \mathrm{~s}^{-1}$.

In conclusion, we have introduced a series of ${ }^{13} \mathrm{C}$ relaxation experiments to study the dynamics of carboxyl and carbonyl groups in protein side chains. The results provide information on processes on both fast (sub-ns) and slower (approximately $\mu \mathrm{s}$ ) time scales that are relevant for understanding the biological function of these groups.

Acknowledgment. We thank Dr. Philippe Pelupessy for many fruitful discussions. This work was supported by the ANR of France (NT05-4_43730), the Swedish Research Council, The Swedish Foundation for Strategic Research, and the Knut and Alice Wallenberg Foundation (M.A.). F.A.A.M. was supported by a FEBS Long-Term Fellowship and by a Marie-Curie fellowship from the European Union (HPMF-CT-2001-01245).

Supporting Information Available: Full caption of Figure 1; figures of other pulse sequences employed; expressions of relevant relaxation rates; a list of parameters used in the analysis of these rates; tables and figures of experimental relaxation rates; tables and figure of local dynamic parameters; a figure illustrating the CSAdependence of local dynamics parameters; spectra illustrating isotopic chemical shifts; a figure supporting the acid-base hypothesis for chemical exchange. This material is available free of charge via the Internet at http://pubs.acs.org.

\section{References}

(1) Palmer, A. G. Chem. Rev. 2004, 104, 3623-3640.

(2) Eisenmesser, E. Z.; Millet, O.; Labeikovsky, W.; Korzhnev, D. M.; WolfWatz, M.; Bosco, D. A.; Skalisky, J. J.; Kay, L. E.; Kern, D. Nature 2005, $438,117-121$.

(3) Mittermaier, A.; Kay, L. E. Science 2006, 312, 224-228.

(4) Malmendal, A.; Evenäs, J.; Forsén, S.; Akke, M. J. Mol. Biol. 1999, 293, $883-899$.

(5) Lee, A. L.; Kinnear, S. A.; Wand, A. J. Nat. Struct. Biol. 2000, 7, 72-77.

(6) Akke, M.; Brüschweiler, R.; Palmer, A. G., III J. Am. Chem. Soc. 1993, 115, 9832-9833.

(7) Mäler, L.; Blankenship, J.; Rance, M.; Chazin, W. J. Nat. Struct. Biol. 2000, 7, 245-250.

(8) Palmer, A. G.; Hochstrasser, R.; Millar, D. P.; Rance, M.; Wright, P. E. J. Am. Chem. Soc. 1993, 115, 6333-6345.

(9) Muhandiram, D. R.; Yamazaki, T.; Sykes, B. D.; Kay, L. E. J. Am. Chem. Soc. 1995, 117, 11536-11544.

(10) Millet, O.; Muhandiram, D. R.; Skrynnikov, N. R.; Kay, L. E. J. Am. Chem. Soc. 2002, 124, 6439-6448.

(11) Brath, U.; Akke, M.; Yang, D.; Kay, L. E.; Mulder, F. A. A. J. Am. Chem. Soc. 2006, 128, 5718-5727.

(12) Skrynnikov, N. R.; Mulder, F. A. A.; Hon, B.; Dahlquist, F. W.; Kay, L. E. J. Am. Chem. Soc. 2001, 123, 4556-4566.

(13) LeMaster, D. M.; Kushlan, D. M. J. Am. Chem. Soc. 1996, 118, 92559264.

(14) Teilum, K.; Brath, U.; Lundström, P.; Akke, M. J. Am. Chem. Soc. 2006, 128, 2506-2507.

(15) Boyer, J. A.; Lee, A. L. Biochemistry 2008, 47, 4876-4886.

(16) Boyd, J. J. Magn. Reson. B 1995, 107, 279-285.

(17) Buck, M.; Boyd, J.; Redfield, C.; Mackenzie, D. A.; Jeenes, D. J.; Archer, D. B.; Dobson, C. M. Biochemistry 1995, 34, 4041-4055.

(18) Mulder, F. A. A.; Skrynnikov, N. R.; Hon, B.; Dahlquist, F. W.; Kay, L. E. J. Am. Chem. Soc. 2001, 123, 967-975.

(19) Berglund, H.; Baumann, H.; Knapp, S.; Ladenstein, R.; Härd, T. J. Am. Chem. Soc. 1995, 117, 12883-12884.

(20) Wilkinson, T. A.; Botuyan, M. V.; Kaplan, B. E.; Rossi, J. J.; Chen, Y. J. Mol. Biol. 2000, 303, 515-529.

(21) Segawa, T.; Kateb, F.; Duma, L.; Bodenhausen, P.; Pelupessy, P. ChemBioChem 2008, 9, 537-542.

(22) Iwahara, J.; Jung, Y.-S.; Clore, G. M. J. Am. Chem. Soc. 2007, 129, 29712980.

(23) Svensson, L. A.; Thulin, E.; Forsén, S. J. Mol. Biol. 1992, 223, 601-606.

(24) Pasat, G.; Zintsmaster, J. S.; Peng, J. W. J. Magn. Reson. 2008, 193, 226232.

(25) Hu, J. S.; Bax, A. J. Am. Chem. Soc. 1996, 118, 8170-8171.

(26) Mulder, F. A. A.; Akke, M. Magn. Reson. Chem. 2003, 41, 853-865.

(27) Hansen, D. F.; Kay, L. E. J. Biomol. NMR 2007, 37, 245-255.

(28) Mulder, F. A. A.; de Graaf, R. A.; Kaptein, R.; Boelens, R. J. Magn. Reson. 1998, 131, 351-357.

(29) Massi, F.; Johnson, E.; Wang, C.; Rance, M.; Palmer, A. G. J. Am. Chem. Soc. 2004, 126, 2247-2256.

(30) Shaka, A. J.; Lee, C. J.; Pines, A. J. Magn. Reson. 1988, 77, 274-293.

(31) Geen, H.; Freeman, R. J. Magn. Reson. 1991, 93, 93-141.

(32) Shaka, A. J.; Barker, P. B.; Freeman, R. J. Magn. Reson. 1985, 64, 547552.

(33) Emsley, L.; Bodenhausen, G. Chem. Phys. Lett. 1990, 165, 469-476.

(34) Emsley, L.; Bodenhausen, G. Chem. Phys. Lett. 1990, 168, 297-303.

(35) Palmer, A. G., III; Skelton, N. J.; Chazin, W. J.; Wright, P. E.; Rance, M. Mol. Phys. 1992, 75, 699-711.

(36) Ferrage, F.; Pelupessy, P.; Cowburn, D.; Bodenhausen, G. J. Am. Chem. Soc. 2006, 128, 11072-11078.

(37) Kumar, A.; Grace, R. C. R.; Madhu, P. K. Prog. NMR Spectrosc. 2000, 37, 191-319.

(38) Pelupessy, P.; Espallargas, G. M.; Bodenhausen, G. J. Magn. Reson. 2003, $161,258-264$

(39) Lipari, G.; Szabo, A. J. Am. Chem. Soc. 1982, 104, 4546-4559.

(40) Loth, K.; Pelupessy, P.; Bodenhausen, G. J. Am. Chem. Soc. 2005, 127, 6062-6068.

(41) Gardiennet-Doucet, C.; Henry, B.; Tekely, P. Prog. Nucl. Magn. Reson. Spectrosc. 2006, 49, 129-149.

(42) Gu, Z. T.; Zambrano, R.; McDermott, A. J. Am. Chem. Soc. 1994, 116, 6368-6372.

(43) Mikhailov, D.; Daragan, V. A.; Mayo, K. H. J. Biomol. NMR 1995, 5, 397-410.

(44) Zheng, Y.; Yang, D. W. J. Biomol. NMR 2004, 28, 103-116.

(45) Kördel, J.; Skelton, N. J.; Akke, M.; Palmer, A. G.; Chazin, W. J. Biochemistrv 1992, 31, 4856-4866.

(46) Kesvatera, T.; Jönsson, B.; Thulin, E.; Linse, S. Proteins: Struct., Funct. Genet. 2001, 45, 129-135.

JA803794G 